\title{
Effectiveness of increase health volunteer ability program in basic care for the dependent elderly in the communities, Nakhon Pathom Province, Thailand
}

\author{
Premwadee Karuhadej, Monrudee Popijan and Prapaiwan Danpradit \\ College of Nursing and Health, \\ Suan Sunandha Rajabhat University, Bangkok, Thailand
}

\begin{abstract}
Purpose - The purpose of this paper is to study and compare knowledge and skills in basic care for the dependent elderly of health volunteers before and after the increase in ability program participation. Design/methodology/approach - Quasi experimental research includes one group pretest-posttest design. The research was conducted from January to March 2018. The samples were 30 health volunteers in Nakorn Pathom Province selected by purposive sampling. They were all female, aged 20-50 years, with minimal education level of early secondary school and were current or former health volunteers. The increase ability program consisted of lecture and skill practice by demonstration and individual replay demonstration. The program duration was $30 \mathrm{~h}$ with $19 \mathrm{~h}$ of skill practice and 2 days of site visit to the dependent elderly' homes. The tool for collecting data was a questionnaire for the evaluation of knowledge and skills in basic care for the dependent elderly. The data were analyzed by means, standard deviation and paired $t$-test.

Findings - After the increase in ability program participation, the health volunteers had very good level of knowledge in basic care for the dependent elderly with statistical significance $(p<0.01)$ and had most correct skills in basic care for the dependent elderly with a score of 9 from 11 items.

Originality/value - Knowledge and skills in basic care for the dependent elderly of the health volunteers increased to a very good level after program participation. Thailand should provide periodic and continuous training program to increase health volunteers' knowledge and skills in basic elderly care to provide care for the elderly with most benefits.
\end{abstract}

Keywords Basic care, Dependent elderly, Increase health volunteer ability, Thailand

Paper type Research paper

\section{Background}

At present, Thailand is projected toward becoming a complete ageing society by 2021[1]. In 2016, Thailand had 10,014,699 (14.90 percent) of the population[2] who were 60 years old and above, which was the second highest proportion of elderly in the ASEAN countries, preceded by Singapore. In 2017, this number increased to $11,000,000$ (16.50 percent) who made up the 60 years old and above population[3]. Two significant reasons for the rapid increase in the elderly population are as follows: decrease in the reproductive or birth rate, and increase in the life expectancy of Thai people. The life expectancy of men and women is currently 72 and

(C) Premwadee Karuhadej, Monrudee Popijan and Prapaiwan Danpradit. Published in Journal of Health Research. Published by Emerald Publishing Limited. This article is published under the Creative Commons Attribution (CC BY 4.0) licence. Anyone may reproduce, distribute, translate and create derivative works of this article (for both commercial and non-commercial purposes), subject to full attribution to the original publication and authors. The full terms of this licence may be seen at http:// creativecommons.org/licences/by/4.0/legalcode

The researcher would like to thank the President of Suan Sunandha Rajabhat University, The Director of the Institute for Research and Development and the university officials who helped process the research fund to be granted by the National Research Institute.

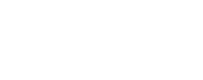


JHR

33,3

220

79 years, respectively. It is predicted that, in the next 10 years, the life expectancy of men and women will be 76 and 83 years, respectively[1]. The impact on Thai society when the elderly population increases include a larger proportion of dependent elderly who need hospitalization, an increase in expense for medical supplies, increase in hospital beds and increase in the need for health personnel for elderly care. The impact on the elderly and their families include an increase in the dependent and bed-ridden elderly. In addition, the elderly who are still ambulatory must still be taken to the hospital for appointments by their sons, daughters or relatives. If they are not available to take the elderly, they have to hire motorcycles or vans making access to health services difficult[4]. Most of today's elderly population do not have prior knowledge of health[5] and lack an income[6]. Therefore, it is a burden on the family to find caregivers to provide care to the elderly at home since hospitals are unable to support the rising and increasing needs of the growing elderly population. Thailand's family status has gradually moved toward single families of which there is a 33.33 percent rate in the Nakhon Pathom Province. The Thai government's awareness of ethics and the life values of the elderly have resulted in arrangements for health volunteers to provide care for the elderly to replace insufficient beds, health personnel and the increasing single-family status in the nation. The related law, legislated and published in the Royal Gazette in 2011, states that there will be a sustainable program to increase knowledge and a monthly salary for health volunteers as well as guidelines for health volunteer selection. Each village or community will select health volunteers from the people in the community who are willing to participate and devote time to public health work $[7,8]$. If the health volunteers have adequate knowledge of basic elderly care, they should be able to better help the health teams and families. However, the health volunteer training projects for elderly care does not cover all areas and is not updated to current levels of medical knowledge and skills. There are increasing numbers of health volunteers, for example the Nakhon Pathom Province has 10,599 volunteers[9], who became volunteers before the Act in 2011 that required an increase in health knowledge of the health volunteers. Based on literature review, 50-70 percent of health volunteers were educated to primary and early secondary level[10-13]. They had insufficient essential knowledge and skills, so they were not confident in their care of the elderly[14-16]. It is, therefore, necessary to increase the health volunteer's knowledge and skills related to the care of the elderly. Nakhon Pathom Province has 72,700 people who are 60 years old and above which is the sixth highest rate compared to the 26 provinces in Central Thailand, so it is necessary to increase knowledge and skills in elderly care amongst health volunteers[17]. This research aims at studying the effectiveness of the program to increase health volunteer ability in basic care for the dependent elderly in the communities of Nakhon Pathom Province.

\section{Research objectives}

The objective of this paper is to study the effectiveness of the program to increase health volunteer ability in basic care for the dependent elderly in the communities of Nakhon Pathom Province.

\section{Research hypothesis}

After participating in the program, the health volunteers had increased their knowledge and improved in their skills in the basic care of the dependent elderly compared to ratings before program participation.

\section{Research framework}

The researcher applied Bloom's learning theory[18] as the program framework to increase the health volunteers' abilities in basic care for the dependent elderly in the communities. Bloom classified individual learning objectives into three domains: cognitive domain - teaching to 
achieve knowledge; affective domain - the attitude of learners toward the subject; and psychomotor domain - the ability to practice after learning. The researcher applied the cognitive domain by teaching the health volunteers about the present situation of Thai elderly, the concept of the elderly, diseases and symptoms in the dependent elderly and theory of skills needed to learn before practising basic health care skills for the elderly. But increasing knowledge in the cognitive domain is associated with each person's affective domain that is defined as a feeling that occurs from a previous phenomenon. For the purpose of this research, the affective domain is the attitude of the volunteers toward basic health care services for the elderly. The psychomotor domain in this research involved teaching with a demonstration, individual replay demonstrations and essential skills practice to enable the health volunteers to provide basic health care to the dependent elderly. The program in this research applied Bloom's learning theory of cognitive and psychomotor domains. Studies on the health volunteers' attitude toward elderly care were conducted which showed different results. There were attitudes of high level[19, 20], average level $[21,22]$ and low level[23]. Since the health volunteers were selected by the villagers from the people who were willing to help the sick people in the communities[7], the researcher did not study the affective domain from Bloom's learning theory[18]. The contents and skills of the elderly care were modified from the curriculum of the Health Promotion Bureau, Department of Health, Ministry of Public Health[24]. The research framework is summarized as shown in Figure 1.

\section{Methodology}

The research design was a quasi-experimental research study comprising of a single group pretest-posttest design.

\section{Population and samples}

The study population were 260 health volunteers in the communities of Nakhon Pathom Province. The selection criteria for study samples were: female, aged 20-50 years, educated to early secondary school and above and current or former health volunteers. There were 30 participants selected by purposive sampling with multistage random sampling from eight districts in Nakhon Pathom Province. The sample size of 30 was determined by Polit's table[25] with a power of test $=0.80$, confidence interval $=0.05$ and an effect size $=0.60$.

The research tools were the following:

The program to increase the health volunteers' ability in basic care for the dependent elderly was conducted by relevant lectures and knowledge content and skills practice by demonstration for at least three individual replay demonstrations. The total duration was $30 \mathrm{~h}$ with $12 \mathrm{~h}$ of skills practice and 2 days of site visits to homes of the dependent elderly. The skills practice sessions included vital signs measurement, sterile technique, care for daily activities, pressure sore wound dressing, drug use in the elderly, care for gastrointestinal problems, and care for respiratory problems, exercise and emergency assessment.

Independent variables

\begin{tabular}{|l|l|}
\hline $\begin{array}{l}\text { Program to increase health volunteers } \\
\text { ability }\end{array}$ & $\begin{array}{l}\text { - Knowledge of health volunteers } \\
\text { in basic care for the dependent } \\
\text { elderly }\end{array}$ \\
$\begin{array}{l}\text { - Knowledge concerning dependent } \\
\text { elderly (cognitive domain) }\end{array}$ & $\begin{array}{l}\text { - Skills of health volunteers in } \\
\text { basic care for the dependent } \\
\text { elderly }\end{array}$ \\
$\begin{array}{l}\text { Demonstration and replay } \\
\text { (psychomotor domain) }\end{array}$ & \\
\hline
\end{tabular}

Health volunteer ability program 
The schedules of the program to increase the health volunteers' ability in basic care for the dependent elderly were made up of the following:

- day 1 - lecture on the present elderly situation, the concept of the elderly, diseases and common symptoms in the dependent elderly, demonstration and replay demonstration of vital signs measurement, sterile technique and instrument cleaning;

- day 2 - lecture, demonstration and replay demonstration of bedding for the active and inactive elderly, care for daily activities such as cleaning body, mouth, teeth, hair washing on the bed and body wiping for fever;

- day 3 - lecture, demonstration and replay demonstration of wound types, wound dressing for general wounds, pressure sore wounds and tracheostomy wounds, drug use in the elderly, common drugs and side effects, insulin injection and dextrostix testing;

- day 4 - lecture, demonstration and replay demonstration of care for the patients with gastrointestinal problems, preparing liquid diets, nasogastric tube feeding and care for the patients with respiratory problems; and

- day 5 - lecture, demonstration and replay demonstration of exercise in bed and emergency assessment of the elderly.

Data collection tools consisted of the following:

- General information on the samples - age, occupation, education level, income, elderly care experiences and duration of health volunteer work. The forms consisted of multiple choice answers and filling in the blanks.

- Questionnaire for knowledge assessment with 25 items of true, false or uncertain answers: each item was scored 1 for the right answer and 0 for the wrong answer.

- Questionnaire for assessment of skills in basic elderly care: the items with most, average and least correct skills were scored 3, 2 and 1, respectively. There were six items for scoring criteria as follows: able to explain the objective; able prepare all tools of practising skills; able to tell how to prevent danger if error occurred; able to perform with sterile technique; able to complete every step; and able to perform with neatness.

Score interpretation is as follows:

- most correct skills (3) = complete fifth and sixth items;

- average correct skills (2) = complete third and fourth items; and

- $\quad$ least correct skills (1) = complete first and second items.

The research tools were checked for content validity by three experts. They were corrected as advised and tested with the volunteers who were not part of the sample group. The reliability index for knowledge was calculated by KR-20 and revealed $r=$ 0.89. The skills of basic care for the elderly was calculated by Cronbach's $\alpha$ coefficient and revealed $r=0.90$

Data collection of knowledge was conducted on the first day of program participation before lecture (pre-test) and on the last hour of the program (post-test). The skills of elderly care were assessed individually before demonstration (pre-test) and after the third replay demonstration (post-test). 
First, personal information was analyzed by percentage. Second, knowledge and skills of basic care for the dependent elderly and pre and post-program participation were analyzed by the mean, standard deviation and paired $t$-test.

Protection of samples' right

The research was approved for ethical consideration by Suan Sunandha Rajabhat University,

Certificate Number COA 1-060/2017, and the researcher conducted the research with consideration of confidentiality and impact on the subjects throughout the research.

\section{Results}

The results showed:

Fifty percent of the samples were 30-40 years old, 53.33 percent were married, 66.67 percent were educated to early secondary school level, 33.33 percent had experiences in elderly care, 83.33 percent had experiences in health volunteer work and 23.33 percent had obtained basic elderly care training.

Before participating in the program, the health volunteers had a good level of knowledge in basic care for the dependent elderly. After program participation, they had a very good level of knowledge with statistically significant increase before the program $(p<0.01)$ as Table I. Before participating in the program, the health volunteers had a very good level of correct knowledge of 10 from 25 items (40.00 percent) and after program participation, they had a very good level of correct knowledge of all 25 items (100.00 percent). The ten items of very good level of correct knowledge both before and after program participation were: checking for an irregular pulse; bedding must be smooth to prevent pressure sores; turning off fan during wiping the elderly; never lift the urinary bag above the urinary bladder in the elderly with retained catheter; dark urine in the urinary bag indicates dehydration; cloudy urine in the urinary bag requires a doctor's consultation; turning over the bedridden elderly every $2 \mathrm{~h}$; dressing pressure sore wounds each time diapers are changed; sputum suction must be performed following a sterile technique; and emergency symptoms that need transfer to hospital are high fever, chill and high or low blood pressure.

Before program participation, the health volunteers had average correct levels of skills in basic care for the dependent elderly. After the program, they had improved correct levels of skills with statistically significant increase before the program $(p<0.01)$ as detailed in Table II. For each skill item after program participation, the health volunteers had the most correct levels of skills in basic elderly care of 9 from 11 items (81.81 percent). Before program participation, they had the most correct level of skills in basic elderly care of 1 from 11 items (9.09 percent) as detailed in Table III.

\begin{tabular}{|c|c|c|c|c|c|c|c|}
\hline Items & Full scores & Mean & SD & Scores level & Paired $t$-test & $p$-value & \multirow{5}{*}{$\begin{array}{l}\text { Table I. } \\
\text { Comparison of health } \\
\text { volunteers' knowledge } \\
\text { before and after } \\
\text { program participation }\end{array}$} \\
\hline \multicolumn{7}{|c|}{ Knowledge in basic elderly care } & \\
\hline Before program & 25 & 17.40 & 3.47 & Good & \multirow[t]{3}{*}{-8.65} & \multirow[t]{3}{*}{$0.001^{* *}$} & \\
\hline After program & 25 & 22.56 & 2.04 & Very good & & & \\
\hline \multicolumn{5}{|c|}{ Notes: $n=30 . * * p<0.01$} & & & \\
\hline
\end{tabular}


JHR

33,3

224

Table II.

Comparison of health volunteers' skills in basic elderly care, before and after program participation

\section{Discussion}

The research showed the followed:

Before participating in the program, the health volunteers had a good level of knowledge in basic care for the dependent elderly. However, after program participation, they had a very good level of knowledge with a statistically significant increase in knowledge compared to before the program $(p<0.01)$ as shown in Table I. Before participating in the program, the health volunteers had a very good level of correct knowledge of 10 from 25 items (40.00 percent) but after program participation, their knowledge was correct on all 25 items (100.00 percent).

Before program participation, the health volunteers had an average level of correct skills in basic care for the dependent elderly. After the program, they had the most correct level of skills with a statistically significant increase compared to before the program $(p<0.01)$.For each skill item after program participation, the health volunteers had the most correct levels of skills in basic elderly care of 9 from 11 items (81.81 percent). This contrasts sharply with skills levels before participating in the program which was at 1 from 11 items (9.09 percent).

The results of this research complied with the research hypothesis. This showed that the program was effective in increasing the health volunteers' ability. It is further consistent with the research of Sanprasan et al.[12] that found that after capacity building based on a participatory learning program, the health volunteers increased knowledge in cardiovascular diseases with statistical significance $(p<0.01)$. Each health volunteer had a very good knowledge level of basic care in patients with cardiovascular diseases, passed assessments for skills in cardiovascular evaluation and 100.00 percent of them had good

\begin{tabular}{lccclll}
\hline Items & Full scores & Mean & SD & Scores level & Paired $t$-test & $p$-value \\
\hline Skills in basic elderly care & & & & & & $0.001^{* *}$ \\
Before program & 3 & 2.13 & 0.21 & Average & -11.24 & \\
After program & 3 & 2.61 & 0.13 & Good & & \\
Notes: $n=30 . * * p<0.01$ & & & & & \\
\end{tabular}

Table III.

Health volunteers' skills in basic care for the dependent elderly, before and after program participation

\begin{tabular}{|c|c|c|c|c|c|c|}
\hline \multirow[b]{2}{*}{ Skills in basic care } & \multicolumn{3}{|c|}{$\begin{array}{l}\text { Average scores before the } \\
\text { program (full score }=3 \text { ) }\end{array}$} & \multicolumn{3}{|c|}{$\begin{array}{l}\text { Average scores after the } \\
\text { program (full score }=3 \text { ) }\end{array}$} \\
\hline & $\bar{X}$ & $\mathrm{SD}$ & Correct level & $\bar{X}$ & $\mathrm{SD}$ & Correct level \\
\hline Vital signs measurement & 2.63 & 0.61 & Most & 2.93 & 0.25 & Most \\
\hline Sterile technique and cleaning instruments & 2.06 & 0.44 & Average & 2.63 & 0.49 & Most \\
\hline Occupation bed & 2.26 & 0.63 & Average & 2.83 & 0.37 & Most \\
\hline Care for daily activities & 2.30 & 0.59 & Average & 2.66 & 0.47 & Most \\
\hline Urinary bladder care & 2.02 & 0.49 & Average & 2.50 & 0.51 & Most \\
\hline Wound dressing & 2.00 & 0.37 & Average & 2.56 & 0.50 & Most \\
\hline Drug use in the elderly & 1.83 & 0.46 & Average & 2.30 & 0.46 & Average \\
\hline Care for patients with GI problems & 2.13 & 0.34 & Average & 2.53 & 0.51 & Most \\
\hline Care for patients with respiratory problems & 2.13 & 0.62 & Average & 2.53 & 0.51 & Most \\
\hline Exercise in bed & 2.10 & 0.67 & Average & 2.86 & 0.34 & Most \\
\hline Emergency assessment & 1.99 & 0.58 & Average & 2.36 & 0.49 & average \\
\hline Note: $n=30$ & & & & & & \\
\hline
\end{tabular}


skills levels of basic cardiopulmonary resuscitation. It was also consistent with the research of Anunta and Tonganake[13], which found that the health volunteers' knowledge and skills in home visits increased with statistical significance $(p<0.01)$ after training. This is also consistent with the research of Jitbantad et al.[10], which found that the health volunteers who joined the capacity building of community volunteers to be case managers of community-dwelling elderly with disabilities had an increase in knowledge theory and practice with the most increase in basic knowledge of elderly disabled rights (97.34 percent) and in health assessment and screening (95.78 percent). This result could be due to demonstration and individual replay demonstrations during which the lecturer divided the participants into groups of eight with close practice, supervision and explanation until the participants were confident enough to give care. The sample subjects were very interested in learning and were satisfied with program participation to a very high level.

\section{Conclusion}

After participating in the program, the health volunteers increased their knowledge and skills in basic care for the dependent elderly. This could help reduce the burden on the shortage of health teams in communities. Thailand should provide periodic and continuous training programs for health volunteers to increase their knowledge and skills in basic elderly care in order to provide optimum care for the elderly.

\section{Limitations}

This research could not be conducted by a quasi-experimental research involving the two group pretest-posttest design because the experiment duration was seven days. Furthermore, the experiment focused on increasing the basic skills in the elderly care of the subjects. The control group could not be totally controlled since they could easily access the knowledge media from YouTube and the internet. Additionally, the data collection of the control group was difficult because the subjects were scattered throughout Nakhon Pathom Province.

\section{References}

1. Prasatkul P. Situation of the Thai elderly. Nakhon Pathom: Institute of Population and Social Research, Mahidol University, Foundation of Thai Gerontology Research and Development; 2014: 4-6.

2. National Statistical Office [NSO]. The survey of the older persons in Thailand. Bangkok: Statistical Forecasting Bureau National Statistical Office, The Government Complex and Text and Journal Publication; 2014: 1-10.

3. Prasatkul P. Situation of the Thai elderly 2016. Nakhon Pathom: Institute for Population and Social Research, Mahidol University, Foundation of Thai Gerontology Research and Development; 2017: 6-8.

4. Tapasee W, Piyachaiwut N, Jaidee C, Piyarattanawat S. Life styles of the homebound elderly in Wang Taku subdistrict, Nakhon Pathom province. SSRU J Nurs Health. 2018; 1(1): 28-34 (in Thai).

5. Nilnate W, Hengpraprom S, Hanvoravongchai P. Level of health literacy in Thai elders, Bangkok. Thai J Health Res. 2016; 30(5): 315-21.

6. Kanthawee P, Pongpanich S, Taneepanichskul S, Meenuck P, Maiarin R, Hansudewe-Chakul C. Quality of life, psychosocial health and health care among aging people in Chiang-Rai province, Thailand: the first phase. J Health Res. 2014; 28(5): 343-52. 
7. Royal Gazette: Ministry of Public Health Order for the village health volunteers, 2011. 128(33 D): 1-2 (in Thai). Mar 20. [cited 2017 Nov 22]. Available from: www.ratchakitcha.soc.go.th/DATA/ $\mathrm{PDF} / 2554 / \mathrm{E} / 145 / 61 . \mathrm{PDF}$

8. Royal Gazette: Ministry of Public Health Order with the repeal of the Ministry of Public Health with the disbursement of money for the village health volunteers 2009, 2018. 135(152 D): 1-15 (in Thai). [cited 2017 Nov 22]. Available from: www.ratchakitcha.soc.go.th/DATA/PDF/2 561/E/152/1.PDF

9. Nakhon Pathom Provincial Administration Organization. Name list and address of health volunteers and families categorized by Tambol and Amphur, 2011. [cited 2017 Nov 20]. Available from: www.thaiphc.net/phc/phcadmin/administrator/Report/OSMRP00002.php

10. Jitbantad W, Ruangput P, Sahairak S, Warapeang W. Capacity building of volunteers to be case manager of community dwelling elderly with disabilities. Nonthaburi: Health System Research Institute; 2017.

11. Phaipong S, Pinitsoontorn S. Village health volunteers' knowledge and role in community health planning in Phen district, Udon Thani province. Community Health Development Quarterly, Khon Kaen University. 2017; 4(2): 291-305 (in Thai).

12. Sanprasan P, Wattradul D, Jamsomboon K, Puapairoj V, Techangkul L, Yuyuen Y. Effects of health volunteer's capacity building based on participating learning program on knowledge and skill of caring patients with cardiovascular disease and a risk group of cardiovascular disease. Thai J Cardiothoracic Nurs. 2015; 6(1): 119-32.

13. Anunta $\mathrm{P}$, Tonganake $\mathrm{J}$. The effectiveness of home visit and training program in village health volunteers in Khwao, Selaphum, Roi Et. J of Office DPC6, Khon Kaen. 2012; 20(1): 1-8 (in Thai).

14. Eamsamai S, Mhuansit R, Thongmag C. An elderly care model among caregiving volunteers at Phukrang Municipality, Amphur Praputthabat, Saraburi Province. Nurs J Ministry Pub Health. 2003; 22(3): 78-87.

15. Supawantanakul D, Sangsirimongkolying R, Mathurasa L, Soottitantawat S, Siringam K. Capacity development of diabetic patient-supporting village health volunteers in Thadindum subdistrict, Chai Badran district, Lopburi province. Phranakhon Rajabhat Res J (Science and Technology). 2016; 11(1): 1-12.

16. Kasemsuk W, Koshakri R. The need to improve of health volunteer's ability in home visit for diabetes people in communities. J Royal Thai Army Nurses. 2015; 16(2): 59-68.

17. Institute for Population and Social Research [IPSR] Population aging in Thailand. Nakhon Pathom: IPSR; 2014: 1-2.

18. Bloom BS. Taxonomy of education objective handbook: domain. New York, NY: David McKey Company; 1986: 93-110.

19. Sithisart W, Tetjativaddhana P, Kitreerautiwong N, Mekrungrongwong S. Factors related to the performance of village health volunteers in non-communicable disease control. J Health Sci Res. 2015; 9(1): 25-31.

20. Potavech E, Chansamart R, Saowwalak Kosolgitiumpron S, Yupart Y. Factors affecting the performance on basic public health of the village public health volunteers in Srichiangmai district, Nongkhai province. Rajabhat Maha Sarakham University J. 2008; 2(3): 265-74.

21. Sootthasil M, Sasang N, Chusak T. Factors influencing participation in managing to control and prevention the spread of contagious disease: the border area of the village public health volunteer in Phusang District, Phayao Province. J Royal Thai Army Nur. 2017; 18(1): 83-92 (in Thai).

22. Limhoklai, N, Yothaka Pakapong, Y, Ratchanagul, P. Effectiveness of a capacity building program for village health volunteers on knowledge and attitude toward emergency medical services of people in Nongsua district, Pathumthani province. Nurs J. 2015; 42(3): 106-8. 
23. Mingmai K, Mungkhunthod S, Arsa R. Knowledge, attitude and performance in care of people with disabilities among village health volunteers in Nong Hoi sub-district, Phra Thong Kham district, Nakhon Ratchasima province. Proceeding of the Second Academic Conference on Graduate Research Presentation, Mahasarakham Rajabhat University; 2017: 1721-29.

\section{Health volunteer ability program}

24. Piensriwatchara E. A guide to elderly caregivers training, 70 hours course. Nonthaburi: Department of Health, Ministry of Public Health; 2013: 80-96.

25. Polit DF, Hungler BP. Nursing research: principles and methods. Philadelphia, PA: J.B. Lippincott Company; 1983: 90-112.

\section{Corresponding author}

Premwadee Karuhadej can be contacted at: premwadee.ka@ssru.ac.th 